\title{
KOMPARASI MODEL PEMBELAJARAN TEBAK KATA DENGAN MAKE A MATCH TERHADAP MOTIVASI BELAJAR IPA SISWA KELAS IV SD ISLAM NW LENDANG BUNGA TAHUN PELAJARAN 2016/2017
}

\author{
Aswasulasikin $^{1}$, Dina Fadilah ${ }^{2}$, Nurdiati $^{3}$ \\ PGSD Universitas Hamzanwadi
}

\begin{abstract}
Abstrak
Penelitian ini bertujuan untuk mengetahui perbedaan motivasi belajar IPA siswa yang menggunakan model pembelajaran tebak kata dengan make a match pada siswa kelas IV SD Islam NW Lendang Bunga Tahun Pelajaran 2016/2017. Adapun jenis penelitian yang dipakai dalam penelitian ini adalah penelitian eksprimen. Desain penelitian dalam penelitian ini adalah randomized pretest-posttest comparison group design. Pada desain ini terdapat dua kelompok yang diberikan perlakuan yang berbeda, dimana masing-masing kelas diberikan pre test untuk mengetahui keadaan awal, kemudian masing-masing kelas diberikan pos test yaitu angket untuk mengetahui motivasi belajar setelah penerapan kedua pembelajaran tersebut.

Penelitian ini bertempat di SD Islam NW Lendang Bunga di kelas IV. Waktu penelitian dilaksanakan pada semester satu (ganjil) pada bulan agustus. Populasi dan sampel penelitian ini adalah seluruh kelas IV SD Islam NW Lendang Bunga Tahun Pelajaran 2016/2017. Variabel bebas pada penelitian ini adalah model pembelajaran tebak kata dan make a match, sedangkan variabel terikat dalam penelitian ini adalah motivasi belajar IPA. Instrumen yang digunakan untuk pengumpulan data dalam penelitian ini adalah angket dengan cara memberikan cek list, selanjutnya data yang diperoleh dianalisis dengan menggunakan uji normalitas menggunakan rumus ChiKuadrat, uji homognitas dengan menggunakan rumus $\mathrm{F}$, dan uji hipotesis menggunakan uji-t dengan rumus polled varian.

Berdasarkan data yang didapat pada sebaran angket motivasi pada kondisi awal di kelas tebak kata dan make a match tergolong sedang yaitu nilai rata-rata kelas tebak kata $(60,3)$ dan nilai rata-rata make a match $(60,4)$. Setelah dilakukan pembelajaran dengan menggunkan model pembelajaran tebak kata dan make a match hasil nilai rata-rata angket motivasi belajar siswa meningkat yaitu kelas tebak kata $(67,5)$ sedangkan make a match $(65,3)$ ini tergolong tinggi. Hasil hipotesis menunjukkan bahwa $\mathrm{t}_{\text {hitung }}<\mathrm{t}_{\text {tabel }}$ yaitu $1,053<2,021$ yang berarti Ho ditolak, sehingga dapat disimpulkan bahwa tidak terdapat perbedaan signifikan antara motivasi belajar IPA yang menggunakan model pembelajaran tebak kata dengan make a match di kelas IV SD Islam NW Lendang Bunga Tahun Pelajaran 2016/2017.
\end{abstract}

Kata Kunci : Model pembelajaran tebak kata, make a match dan motivasi belajar.

\section{PENDAHULUAN}

Dalam proses pembelajaran, motivasi merupakan salah satu aspek dinamis yang sangat penting. Sering terjadi siswa yang kurang berprestasi bukan disebabkan oleh kemampuannya yang kurang, tetapi dikarenakan tidak adanya motivasi 
untuk belajar sehingga ia tidak berusaha untuk mengerahkan segala kemampuannya. Dengan demikian bisa dikatakan siswa yang berprestasi rendah belum tentu disebabkan oleh kemampuannya yang rendah pula, tetapi mungkin disebabkan oleh tidak adanya dorongan atau motivasi. Karena proses pembelajaran akan berhasil manakala siswa mempunyai motivasi dalam belajar. Oleh karena itu, guru perlu menumbuhkan motivasi belajar siswa khususnya dalam pembelajaran IPA dengan menentukan suatu model yang sesuai dan dapat menciptakan situasi dan kondisi kelas yang kondusif agar proses pembelajaran dapat berlangsung sesuai dengan tujuan yang diharapkan.

Berdasarkan pengamatan yang telah dilakukan peneliti pada tanggal 30 April 2016 di SD Islam NW Lendang Bunga Kecamatan Aikmel khususnya di kelas IV Tahun Pelajaran 2016/2017 adalah rendahnya motivasi belajar peserta didik terhadap pembelajaran IPA. Hal ini dapat terlihat pada saat kegiatan belajar mengajar sedang berlangsung. Siswa tidak memperhatikan pelajaran yang sedang dijelaskan oleh guru di depan kelas, berbicara dan bermain dengan teman duduknya, bahkan ada siswa yang tidur disaat kegiatan belajar mengajar berlangsung. Hal lain yang membuat kurangnya motivasi belajar IPA yaitu cara guru dalam mengajar. Guru lebih banyak menggunakan metode pembelajaran konvensional terutama pada pembelajaran IPA, guru biasanya membagikan buku paket kepada siswa kemudian guru menjelaskan materi, setelah itu guru meminta siswa untuk mencatat materi yang sudah dijelaskan, baru setelah para siswa selesai guru meminta siswa untuk mengerjakan soal. Sehingga siswa merasa jenuh dalam belajar, hal tersebut secara otomatis membuat suasana belajar siswa kurang menyenangkan.

Untuk mengatasi masalah tersebut, diperlukan suatu model pembelajaran yang tepat, menarik dan efektif sehingga siswa dapat aktif dalam kegiatan pembelajaran. Salah satu model pembelajaran IPA yang dapat melibatkan siswa secara aktif dalam kegiatan pembelajaran adalah dengan menggunakan model pembelajaran kooperatif. Pembelajaran kooperatif akan memberi kesempatan kepada siswa untuk bekerja sama dengan sesama 
siswa dalam tugas-tugas yang diberikan oleh guru untuk mencapai tujuan bersama.

Terdapat berbagai model pembelajaran kooperatif, beberapa diantaranya adalah pembelajaran kooperatif tipe tebak kata dan make a match. Model pembelajaran tebak kata adalah model pembelajaran yang menggunakan media kartu teka teki berpasangan dengan kartu jawaban teka teki (Turniasih, 2013: 28). Pada model pembelajaran ini guru mengajak siswa untuk bermain tebak kata dengan menggunakan media kartu kertas karton. Model tebak kata dilaksanakan dengan cara guru memberikan kartu soal kepada siswa untuk dibacakan kepada pasangannya dan siswa yang lainnya diberikan kartu jawaban yang isinya tidak boleh dibaca kemudian ditempelkan di dahi dan siswa yang mendapat kartu jawaban harus menebak apa yang dimaksud dalam kartu soal. Jawaban tepat bila sesuai dengan isi kartu yang ditempelkan di dahi.

Sedangkan model pembelajaran make a match adalah model pembelajaran yang menggunakan kartu-kartu untuk mempermudah dalam penyampaian materi karena kondisi belajar yang menyenangkan (Lestari, 2013: 26). Make a match dilaksanakan dengan cara guru membagikan kartu soal dan jawaban kepada siswa, kemudian siswa mencari pasangan yang mempunyai kartu yang cocok dangan kartunya (soal jawaban). Model pembelajaran tebak kata dan model pembelajaran make a match ini memiliki kesamaan, yaitu sama-sama menggunakan media kartu (soal jawaban) dengan cara siswanya berpasangan. Sedangkan perbedaannya terletak pada langkahlangkah pengimplementasinya dalam proses pembelajaran.

Melalui strategi tersebut diharapkan pelaksanaan pembelajaran IPA dapat menghilangkan rasa bosan siswa dalam belajar. Siswa dapat saling tukar pikiran dengan temannya dan mampu menguasai materi pembelajaran yang nantinya dapat mempengaruhi motivasi siswa. Berdasarkan uraian di atas peneliti termotivasi melakukan penelitian yang berjudul "Komparasi Model Pembelajaran Tebak Kata dengan Make A Match Terhadap Motivasi Belajar IPA Siswa Kelas IV SD Islam NW Lendang Bunga Tahun Pelajaran 2016/2017" 


\section{METODE PENELITIAN}

Jenis penelitian yang digunakan dalam penelitian ini adalah penelitian eksprimen. Desain penelitian yang digunakan adalah randomized pretest posttest comparison group design. Adapun desain penelitian ini dapat dilihat sebagai berikut:

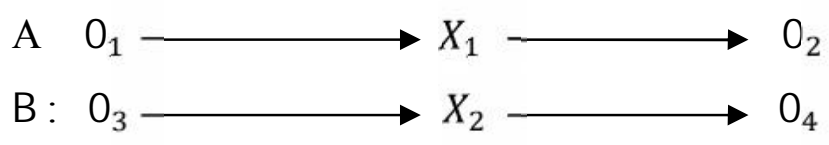

Keterangan:

A : Kelompok eksperimen 1

B : Kelompok eksperimen 2

$0_{1}$ : Pre-test sebelum pelaksanaan model make a match.

$0_{3}$ : Pre-test sebelum pelaksanaan model tebak kata.

$X_{1}$ : Perlakuan terhadap kelas yang dikenai model pembelajaran make a match.

$X_{2}$ : Perlakuan terhadap kelas yang dikenai model pembelajaran tebak kata.

$\mathrm{O}_{2}$ : Post-test sesudah diberikan perlakuan dengan menggunakan model pembelajaran make a match .

$0_{4}$ : Post-test sesudah diberikan perlakuan dengan menggunakan model pembelajaran tebak kata.

Penelitian ini bertempat di SD Islam NW Lendang Bunga. Waktu penelitian dilaksanakan pada semester satu (ganjil) pada bulan agustus.
Populasi dan sampel penelitian ini adalah seluruh kelas IV SD Islam Lendang Bunga Tahun Pelajaran 2016/2017 dengan jumlah siswa 39 orang yang terdiri dari dua kelas yaitu kelas A berjumlah 19 siswa dan kelas B berjumlah 20 siswa. Variabel bebas pada penelitian ini adalah model pembelajaran tebak kata dan make a match, sedangakan variabel terikat dalam penelitian ini adalah motivasi belajar. Teknik pengumpulan data dalam penelitian ini adalah teknik non tes dengan menggunakan instrumen angket.

Data yang diperoleh dianalisis dengan menggunakan uji normalitas menggunakan rumus Chi-Kuadrat yaitu:

$$
\chi^{2}=\frac{\sum\left(f_{0}-f_{h}\right)^{2}}{f_{h}}
$$

Keterangan:

$$
\begin{aligned}
& \chi^{2}=\text { Chi-kuadrat } \\
& f_{0}=\text { frekuensi observasi } \\
& f_{h}=\text { frekuensi harapan }
\end{aligned}
$$


Analisis selanjutnya yaitu uji homognitas dengan menggunakan rumus uji $\mathrm{F}$ dimana rumusnya adalah sebagai berikut:

$$
\mathrm{F}=\frac{\text { Varian terbesar }}{\text { Varrian terkecil }}
$$

Analisis terakhir adalah pengujian hipotesis dengan menggunakan $\mathrm{Uji}-\mathrm{t}$ dengan rumus polled varians yaitu:

$$
\mathrm{t}=\frac{\bar{X}_{1}-\bar{X}_{2}}{\sqrt{\frac{\left(n_{1}-1\right) S_{1}^{2}+\left(n_{2}-1\right) S_{2}^{2}}{n_{1}+n_{2}-2}\left[\frac{1}{n_{1}}+\frac{1}{n_{2}}\right]}}
$$

Keterangan:

$$
\begin{aligned}
\mathrm{X} 1= & \text { Nilai kelompok eksperimen } \\
& \text { pertama } \\
\mathrm{X} 2= & \text { Nilai kelompok eksperimen } \\
& \text { kedua } \\
\mathrm{S} 1= & \text { Varians kelas eksperimen } \\
& \text { pertama } \\
\mathrm{S} 2= & \text { Varians kelas eksperimen } \\
& \text { kedua } \\
\mathrm{n} 1= & \begin{array}{l}
\text { Jumlah sampel eksperimen } \\
\text { pertama }
\end{array} \\
\mathrm{n} 2= & \text { Jumlah sampel eksperimen } \\
& \text { pertama }
\end{aligned}
$$

\section{HASIL DAN PEMBAHASAN}

Pada penelitian ini, peneliti membandingkan motivasi belajar siswa yang menggunakan model pembelajaran tebak kata dengan make a match dengan menggunakan instrumen angket. Adapun data hasil pre test dan post test untuk motivasi belajar adalah sebagai berikut: Berdasarkan data yang sudah terkumpul diperoleh skor terendah untuk pre test angket motivasi belajar yang menggunakan model pembelajaran tebak kata adalah 52 dan skor tertinggi 76 dengan nilai rata-rata 60,3. Sedangkan untuk post tes skor terendahnya adalah 57 dan skor tertingginya 76 dengan nilai rata-rata 67,5. Untuk pre test angket motivasi belajar yang menggunakan model pembelajaran make a match adalah 49 dan skor tertinggi 72 dengan nilai ratarata 60,4. Sedangkan untuk post tes skor terendahnya adalah 51 dan skor tertingginya 74 dengan nilai rata-rata 65,3 .

Sementara itu berdasarkan data tersebut dicari pula mean ideal (Mi) dan standar deviasi ideal (SDi) untuk keperluan pengkateagorian sesuai dengan rumus untuk menentukan $\mathrm{Mi}$ dan SDi. Dimana diperoleh skor maksimum idealnya 4 dan skor minimum idealnya 1 , maka rata-rata ideal (Mi) 50 dan standar deviasi (SDi) 10.

Berdasarkan pengkategorian tersebut mean yang diperoleh untuk pre test yaitu tebak kata $(60,3)$ dan 
make a match $(60,4)$ secara umum dapat digolongkan dalam kategori sedang dan sebaliknya untuk post tes tebak kata $(67,5)$ dan make a match
$(65,3)$ termasuk dalam kategori tinggi. Untuk lebih jelasnya dapat dilihat pada grafik dibawah ini:

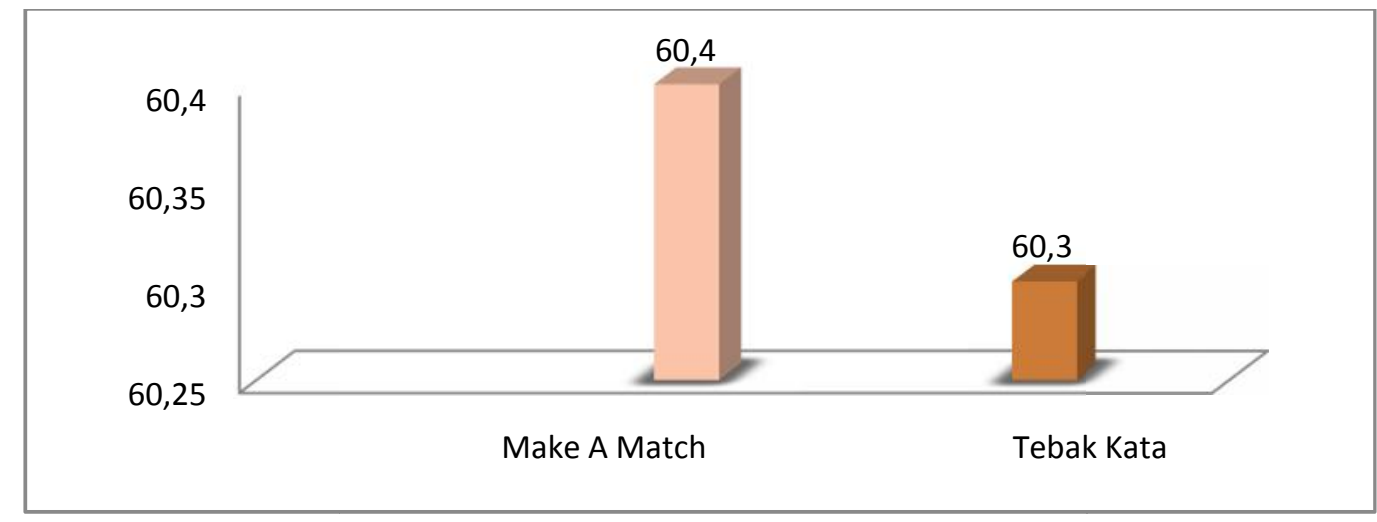

Gambar 1

Grafik Perbandingan Pre Test Angket Motivasi Belajar Siswa yang Menggunakan Model Pembelajaran Tebak Kata dan Make A Match.

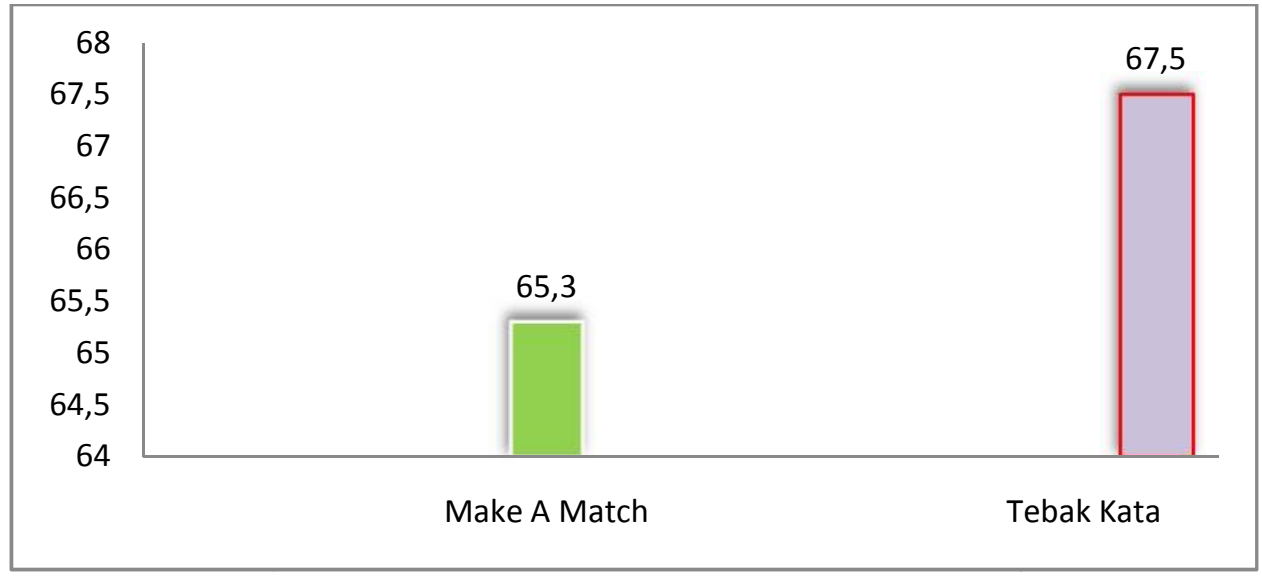

Gambar 2

Grafik Perbandingan Post Test Angket Motivasi Belajar Siswa yang Menggunakan Model Pembelajaran Tebak Kata dan Make A Match.

Data yang didapatkan dianalisis dengan uji normalitas menggunakan
Chi-kuadrat $(\chi 2)$ seperti terlihat pada tabel di bawah ini:

Tabel 1

Uji Normalitas untuk Variabel Tebak Kata dan Make A Match

\begin{tabular}{ccccc}
\hline Variabel & Eksperimen & $\mathrm{X}^{2}$ Hitung & $\mathrm{X}^{2}$ Tabel & Keterangan \\
\hline Tebak Kata & Post test & 7,213 & 9,488
\end{tabular}




\begin{tabular}{rrrrr} 
Make A Match & Post test & 6,373 & 11,070 & Normal \\
\hline terdapat perbedaan & signifikan antara
\end{tabular}

Berdasarkan tabel di atas bahwa harga $\chi^{2}$ hitung lebih kecil dari $\chi^{2}$ tabel ( $\chi_{\text {hitung }}^{2}<\chi_{\text {tabel }}^{2}$ ), ini berarti bahwa kedua variabel yaitu tebak kata dan make a match berdistribusi normal.

Selanjutnya data yang didapat tersebut dianalisis dengan menggunakan uji F. Berdasarkan data pre test didapatkan $\mathrm{F}_{\text {hitung }}=1,09$ dan $F_{\text {tabel }}=2,20$. Berdasarkan data tersebut bahwa $F_{\text {hitung }}$ lebih kecil dari $F_{\text {tabel, }}$ ( $\mathrm{F}_{\text {hitung }}<\mathrm{F}_{\text {tabe }}=1,09<2,20$ ) berarti dapat disimpulkan data tersebut homogen.

Analisis terakhir adalah pengujian hipotesis dengan menggunakan Uji t (polled varians) dan diperoleh $\mathrm{t}_{\text {hitung }}<\mathrm{t}_{\text {tabel}}$, yaitu 1,158 $<$ 2,021 Sehingga Ho ditolak dan Ha diterima. Sehingga dapat disimpulkan tidak terdapat perbedaan signifikan antara motivasi belajar IPA siswa yang menggunakan model pembelajaran tebak kata dengan make a match di kelas IV SD Islam Lendang Bunga Tahun Pelajaran 2016/2017.

\section{KESIMPULAN}

Berdasarkan dari hasil penelitian dapat ditarik kesimpulan bahwa tidak motivasi belajar IPA siswa yang menggunakan model pembelajaran tebak kata dengan make a match di kelas IV SD Islam Lendang Bungan Tahun Pelajaran 2016/2017. Hal ini terbukti berdasarkan hasil pehitungan dari harga $t_{\text {hitung }}=1,158$ lebih kecil dibandingkan dengan $t_{\text {tabel }}=2,021$ dengan kata lain hipotesis Ho ditolak dan Ha diterima.

\section{Saran}

Adapun saran-saran yang dapat diberikan peneliti dari hasil penelitian ini adalah:

1. Diharapkan kepada para guru dan pengelola pendidikan agar lebih memperhatikan model pembelajaran yang digunakan di dalam kelas karena hal itu sangat berpengaruh terhadap motivasi belajar siswa.

2. Siswa diharapkan lebih aktif terlibat dan lebih antusias dalam proses belajar mengajar agar benarbenar mampu memahami, mengerti, dan dapat menerapkan ilmu pengetahuan dalam kehidupan masyarakat.

3. Penelitian ini masih jauh dari kesempurnaan, maka untuk itu 


$$
\begin{aligned}
& \text { peneliti mengharapkan supay } \\
& \text { penilti selanjutnya bisa } \\
& \text { mengungkapkan hal-hal yang } \\
& \text { belum terungkap oleh peneliti yang } \\
& \text { sekarang guna mendapatkan hasil } \\
& \text { yang lebih bagus dari penelitian } \\
& \text { sebelumnya. }
\end{aligned}
$$

\section{DAFTAR PUSTAKA}

Arikunto S. (2010). Manajemen Penelitian. Jakarta: Rineke.

Lestari S. P. (2013). Studi Komparasi Model Pembelajaran Kooperatif Tipe Make A Match Dengan Think Pair Share Pada Mata Pelajaran Akutansi Ditinjau Dari Matra Kognitif Siswa XI IPS SMA Negeri Surakarta Tahun Pelajaran 2012/2013. Tersedia pada http://dglib.unes.ac.id/dokumen/ donload/30601 diakses pada tanggal 24 februari 2016

Sugiyono. (2013). Metode Penelitian Pendidikan Pendekatan Kuantitatif Kualitatif dan $R \& D$. Bandung: Alfabeta . (2013). Statistika untuk Penelitian. Bandung: Alfabeta

Turniasih. (2013) Keefektifan Penerapan Model Tebak Kata Terhadap Minat dan Hasil Belajar PKn Materi Komponen Pemerintahan Pusat di Indonesia Kelas IV SD Negeri Debong Tengah 1, 2 Dan 3 Kota Tegal. Tersedia pada http://unes.ac.id/17305/1/ 1401409016/pdf diakses pada tanggal 9 Desember 2016. 